Check for updates

Cite this: Mater. Adv., 2021, 2, 3099

\title{
Employing lignin in the formation of the selective layer of thin-film composite membranes for pervaporation desalination
}

\author{
Yu-Ting Chen, ${ }^{a}$ Yi-Ming Sun, (D) ${ }^{\text {bc }}$ Chien-Chieh Hu, ${ }^{\text {cd }}$ Juin-Yih Lai ${ }^{\mathrm{cd}}$ and \\ Ying-Ling Liu (D) *ac
}

\begin{abstract}
This work reports a study on employing lignin in the formation of a selective layer of thin-film composite (TFC) membranes for pervaporation desalination. The TFC membranes with lignin-based separation layers are fabricated using a solution-casting method. With a reduction of the separation layer thickness to about $0.47 \mu \mathrm{m}$, a water permeation flux of $18.5 \mathrm{~kg} \mathrm{~h}^{-1} \mathrm{~m}^{-2}$ and a salt rejection of above $99.95 \%$ have been recorded on the lignin based TFC membrane with a feeding solution of $3.5 \mathrm{wt} \% \mathrm{NaCl}_{(\mathrm{aq})}$ at $45{ }^{\circ} \mathrm{C}$. The membrane also exhibits high stability in long-term operation tests and can be applied for operations on high salinity water (up to $15 \mathrm{wt} \% \mathrm{NaCl}_{(\mathrm{aq})}$ ). While being applied to seawater desalination, the membrane exhibits a water permeation flux of about $20.4 \mathrm{~kg} \mathrm{~h}^{-1} \mathrm{~m}^{-2}$ and a salt rejection of above $99.95 \%$ at $45{ }^{\circ} \mathrm{C}$. A membrane separation process, which uses sustainable materials for salty wastewater treatments and water resource generation, has been demonstrated.
\end{abstract}

Received 19th February 2021 Accepted 25th March 2021

DOI: $10.1039 / \mathrm{d} 1 \mathrm{ma} 00150 \mathrm{~g}$

rsc.li/materials-advances formation of the separative layer of thin-film composite (TFC) membrane for pervaporation desalination. ${ }^{15}$ Another $2 \mathrm{D}$ nanomaterial, MXene, ${ }^{16-18}$ has also shown great potential in membrane application for pervaporation desalination. With a target of searching for potential materials for membrane-based pervaporation desalination, this work reports the first study on employing lignin as the raw material for separation membranes on pervaporation desalination based on its hydrophilic and environmentally benign features.

As a biomass, lignin has been used as feedstock and raw material for production of chemicals and agents ${ }^{19-23}$ and as a reactive additive for polymeric materials. ${ }^{24-30}$ Utilization of lignin in membrane modification has also been reported. ${ }^{31-35}$ Ding and coworkers ${ }^{31}$ used lignin-cellulose nanofibrils (LCN) to modify polyethersulfone ultrafiltration membranes showing enhanced membrane hydrophilicity and mechanical strengths. Zhang et al. $^{32}$ modified reverse osmosis membranes with the deposition of alkaline lignin on the surface of separative polyamide layers to gain enhanced salt rejection ability and antifouling properties. Bahi et al. ${ }^{33}$ prepared electrospun ligninzeolite composite nanofibers. Nevertheless, the membranes did not gain significant attraction compared to other polymer-based fibrous membranes. In our previous work, ${ }^{34}$ lignin was used to modify crosslinked polybenzoxazine membranes. Introduction of hydrophilic lignin into the membranes successfully increased the permeation fluxes without sacrificing the membrane selectivity in pervaporation separation on tetrahydrofuran-water mixtures. In another work, we used lignin as a thickener for increasing 
the viscosity of polybenzoxazine solutions for the fabrication of interconnected porous membranes of crosslinked polybenzoxazine for oil-water separation. ${ }^{35}$

Based on the above discussion, this work reports the first study, to our best knowledge, on the preparation of ligninbased dense membranes for pervaporation desalination. With 10 wt\% PVA as a binder, the lignin-based TFC membrane (thickness of the selective layer: $0.47 \mu \mathrm{m}$ ) shows a water permeation flux of about $18.5 \mathrm{~kg} \mathrm{~h}^{-1} \mathrm{~m}^{-2}$ and a salt rejection ratio of about $99.95 \%$ in a feeding solution of $3.5 \mathrm{wt} \% \mathrm{NaCl}_{(\mathrm{aq})}$ at $45{ }^{\circ} \mathrm{C}$. Details of the pervaporation desalination results under various conditions have been examined and discussed in this work.

\section{Experimental}

\section{Materials}

Dealkalined lignin is a commercial product from TCI chemical company and was used as received. PVA with a deacetylation degree of about 99\% was received from Chang Chun Petrochemical Company (Taiwan). Maleic anhydride (99\%) was purchased from Sigma-Aldrich chemical company. Polyacrylonitrile (PAN, molecular weight: $150000 \mathrm{Da}$ ) was obtained from Tong-Hwa Synthetic Fiber Co. Ltd (Taiwan). The PANbased porous layer was applied to a polyester nonwoven fabric using a phase-inversion process. The PAN-nonwoven porous membranes were utilized as the substrates for fabrication of the lignin-based TFC membranes. Reagent grade salts have been used for preparation of the salted water as feeding solutions for pervaporation tests.

\section{Instrumental characterization}

The surface hydrophilicity of the prepared membranes was evaluated with measurements of their water contact angles (WCAs) with a surface analyzer from the First Ten Angstroms Co. (FTA, Model: FTA 1000 B). Fourier transform infrared (FTIR) spectra were recorded on a PerkinElmer Spectrum II FTIR spectrometer equipped with an attenuated total reflectance accessory part. A field-emission scanning electron microscope (SEM) from Hitachi Instrumental Co. (SU 8010) was employed in the observation of membrane morphology.

\section{Preparation of lignin-based TFC membranes}

PVA (1.0 g) was dissolved in $190 \mathrm{~mL}$ water at about $90{ }^{\circ} \mathrm{C}$. After being added with lignin $(9.0 \mathrm{~g})$, the solution was heated at $70{ }^{\circ} \mathrm{C}$ for $12 \mathrm{~h}$. Maleic anhydride $(0.5 \mathrm{~g})$ and $0.5 \mathrm{~mL}$ of acetic acid aqueous solution (10 wt $\%$ ) were added to the solution resulting in the casting solution of lignin/PVA-90 (90 means the weight fraction of lignin over lignin and PVA). Casting solutions with various lignin fractions from $70 \mathrm{wt} \%$ to $90 \mathrm{wt} \%$ were prepared in this work.

The porous PAN-nonwoven substrate $(200 \mu \mathrm{m})$ was treated with a $1.0 \mathrm{M} \mathrm{NaOH}_{(\mathrm{aq})}\left(60{ }^{\circ} \mathrm{C}, 0.5 \mathrm{~h}\right)$ for oxidation of the PAN layer surface, ${ }^{36}$ washed with water, and dried at $50{ }^{\circ} \mathrm{C}$ under a vacuum overnight. To ensure the surface hydrophilicity of the alkali-treated PAN layer of the substrate, the substrate was stored in water prior to use. The substrate was fixed on a glass plate. The casting solution of lignin was applied to the substrate surface with a casting knife in various gaps between 230 and $300 \mu \mathrm{m}$ to adjust the casting solution thickness (about 30-100 $\mu \mathrm{m}$ ) applied on the substrate.

The samples were dried at $45{ }^{\circ} \mathrm{C}$ under a reduced pressure of $60 \mathrm{mmHg}$, and then thermally treated at $120{ }^{\circ} \mathrm{C}$ for $2 \mathrm{~h}$ for crosslinking the lignin/PVA layers. The prepared membrane was coded as L-TFC-X, where X denoted the weight fraction of lignin/(lignin + PVA) in the casting solution.

\section{Pervaporation desalination tests}

A laboratory-assembled facility has been employed for pervaporation desalination tests. ${ }^{34}$ The cell for fixing the membrane gives an effective membrane area $(A)$ of about $15.9 \mathrm{~cm}^{2}$. In the pervaporation desalination operation, the downstream pressure is kept at around 400-667 Pa. While a stable condition is reached, the permeated liquid in a period of collection time $(t$, about $20 \mathrm{~min}$ ) is collected using a liquid nitrogen bath and weighted $(W)$. The data is applied for determination of the permeation flux $(P)$ of the tested membrane according to the equation of $P=W /(A t)$. The collected liquid is applied in a conductivity meter for the determination of the salt concentration of the permeated liquid. The salt rejection $(R \%)$ is calculated from eqn (1)

$$
R(\%)=\left(1-\frac{C_{\mathrm{p}}}{C_{\mathrm{f}}}\right) \times 100 \%
$$

where $C_{\mathrm{p}}$ and $C_{\mathrm{f}}$ is the salt concentration of the permeated liquid and the feeding solution, respectively. Since salt cannot be vaporized, all the salt collected at the back side of the membrane is taken into the calculation of the value of $C_{\mathrm{p}}$.

\section{Results and discussion}

\section{Preparation of lignin-based TFC membranes}

Although filtration-deposition processes have been taken for preparation of 2-D nanomaterials (such as graphene and graphene oxide) based TFC membranes, ${ }^{37}$ this process is not suitable for lignin due to the relatively small size of lignin molecules. In this work, lignin is considered to be a polymeric material to be processed under the conventional solution-casting method for preparation of lignin-based TFC membranes. Nevertheless, for the TFC membrane made with the neat lignin, the lignin layer has a poor adhesion to the porous substrate. To solve this problem, PVA and maleic anhydride are utilized as a binder and a crosslinking agent for lignin, respectively (Fig. 1). ${ }^{38}$ On the other hand, to enhance the interfacial adhesion between the separation layer and the substrate, the PAN-nonwoven substrates have been treated with $1.0 \mathrm{M} \mathrm{NaOH}(\mathrm{aq})$ at $60{ }^{\circ} \mathrm{C}$ in various periods for oxidation of the $-\mathrm{CN}$ groups of the PAN layer to $-\mathrm{COOH}$ moieties. $^{36,39}$ The oxidation reaction has been traced with FTIR analysis and surface WCAs measurements. In FTIR analysis, the absorption intensity of -CN groups at about $2240 \mathrm{~cm}^{-1}$ decreases and the absorption of $-\mathrm{COOH}$ at $3372 \mathrm{~cm}^{-1}$ increases with the 

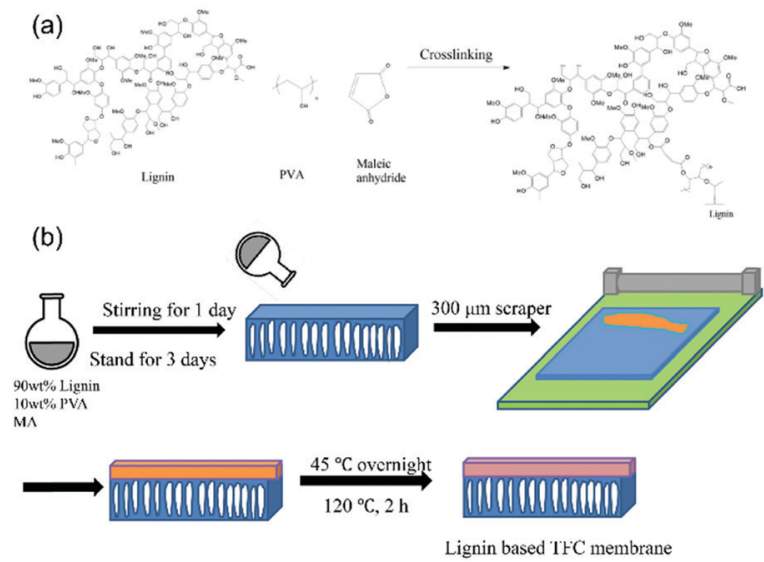

Fig. 1 (a) Chemical structures of lignin and the agents used for preparation of crosslinked lignin based membranes; (b) fabrication of crosslinked-lignin based TFC membranes using a solution-casting method.

increasing treatment time, supporting the occurrence of the oxidation reaction at the $-\mathrm{CN}$ groups of the PAN layer. The oxidation reaction also results in an increase in the surface hydrophilicity of the substrate surface. With a $0.5 \mathrm{~h}$ treatment, the WCA value recorded on the substrate surface drops from $62^{\circ}$ to $11^{\circ}$. Nevertheless, a prolonged treatment time does not result in further decreases in the WCA values, as the membrane within an $1 \mathrm{~h}$ and $1.5 \mathrm{~h}$ treatment gives a WCA value of about $28^{\circ}$ and $52^{\circ}$, respectively. A long reaction time might allow the reagent to penetrate into the PAN layer, resulting in the oxidation reaction taking place in the inner part of the PAN layer. Consequently, the chain mobility of PAN was enhanced and the relatively hydrophobic PAN segments moved toward the membrane surface.

For the preparation of the lignin-based TFC membranes, maleic anhydride is used as a crosslinking agent for lignin. The crosslinking behavior between lignin and maleic anhydride has been traced using FTIR spectroscopy (Fig. 2). The performance of the crosslinking reaction is supported by the decrease in the

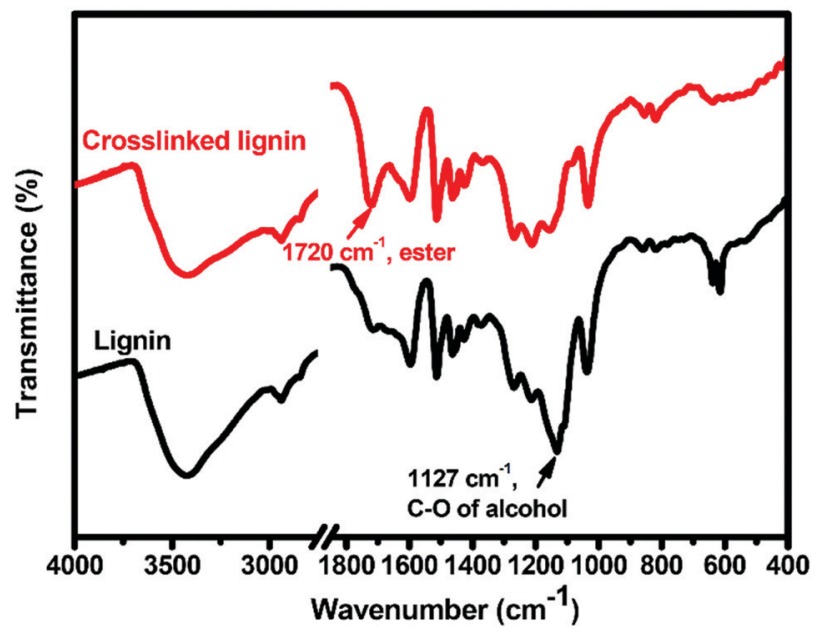

Fig. 2 FTIR spectra recorded on lignin samples to trace the crosslinking behavior of lignin with maleic anhydride.

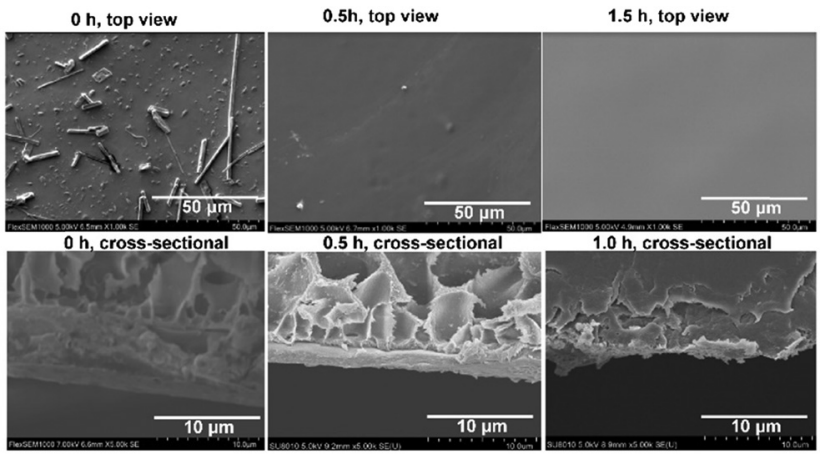

Fig. 3 SEM micrographs of L-TFC-50 membranes made with the oxidized PAN supporting layers under different oxidization times.

absorption peak of $\mathrm{C}-\mathrm{O}$ linkages at $1127 \mathrm{~cm}^{-1}$ and the increase in the absorption peak of ester groups at $1720 \mathrm{~cm}^{-1}$. The absorption of maleic anhydride at $1780 \mathrm{~cm}^{-1}$ and $1856 \mathrm{~cm}^{-1}$ are not observed for the crosslinked lignin sample, further supporting the crosslinking reaction between lignin and maleic anhydride.

L-TFC-50 membranes constructed with various surface treated substrates have been prepared. The L-TFC-50 membrane constructed with the pristine PAN-nonwoven substrate shows obvious delamination of the separation layer from the substrate after the pervaporation desalination operation. The oxidized layer thickness of the PAN-nonwoven substrates also affects the properties of the corresponding L-TFC-50 membranes. The TFC membranes made with the neat substrate and the 0.5 h-treated substrate possess clear lignin separation layers on the porous substrate (Fig. 3). For the substrate within a $1.0 \mathrm{~h}$ treatment, the corresponding membrane does not show a distinguishable lignin layer on the substrate. The porous structure of the substrate also disappears due to the lignin/PVA casting solution sinking into the porous PAN layer. Based on the results, the 0.5 h-treated substrate is selected for the fabrication of the L-TFC membranes for further examination.

\section{Lignin-based TFC membranes with different lignin fractions}

Toward the preparation of lignin-based TFC membranes, the L-TFC-90 membrane (the selective layer possessing $90 \mathrm{wt} \%$ lignin and $10 \mathrm{wt} \%$ PVA binder) has been fabricated with the 0.5 h-treated substrate. The membranes with lignin contents above $90 \mathrm{wt} \%$ are not successfully obtained due to the delamination between the separation layer and the substrate either in the membrane fabrication process or in pervaporation desalination tests. For comparison, L-TFC-70 and L-TFC-80 membranes are also prepared.

The L-TFC-X membranes have been applied to pervaporation desalination tests on a $3.5 \mathrm{wt} \% \mathrm{NaCl}_{(\mathrm{aq})}$ solution at $25{ }^{\circ} \mathrm{C}$ (Table 1). Although all the membranes show a high salt rejection of above $99.6 \%$, the salt rejection of $99.96 \%$ recorded on the L-TFC-90 membrane is noteworthy. Meanwhile, the L-TFC-90 membrane still exhibits the highest thickness-normalized permeation flux (permeability, $3.0 \mathrm{~kg} \mu \mathrm{m} \mathrm{h}^{-1} \mathrm{~m}^{-2}$ ) among the membranes. The L-TFC-90 membrane has potential for pervaporation desalination 
Table 1 The pervaporation desalination tests on a feeding solution of $3.5 \mathrm{wt} \%$ $\mathrm{NaCl}_{(\text {aq) }}$ at $25^{\circ} \mathrm{C}$ with various lignin-based TFC membranes

\begin{tabular}{lllll}
\hline & $\begin{array}{l}\text { Separation } \\
\text { layer } \\
\text { thickness } \\
(\mu \mathrm{m})\end{array}$ & $\begin{array}{l}\text { Permeation } \\
\text { flux } \\
\left(\mathrm{kg} \mathrm{h}^{-1} \mathrm{~m}^{-2}\right)\end{array}$ & $\begin{array}{l}\text { Permeability } \\
\left(\mathrm{kg} \mu \mathrm{m} \mathrm{h}^{-1} \mathrm{~m}^{-2}\right)\end{array}$ & $\begin{array}{l}\text { Salt } \\
\text { rejection } \\
(\%)\end{array}$ \\
\hline Membrane & & $3.9 \pm 0.20$ & $2.6 \pm 0.13$ & 99.74 \\
L-TFC-70 & 0.67 & $5.0 \pm 0.38$ & $2.7 \pm 0.21$ & 99.79 \\
L-TFC-80 & 0.55 & $3.7 \pm 0.16$ & $3.0 \pm 0.10$ & $>99.95$
\end{tabular}

applications. More test results on the L-TFC-90 membrane are discussed below.

\section{Pervaporation desalination within the L-TFC-90 membrane}

For TFC membranes, the relatively small thickness of the separative layer is attractive for reduction of permeation resistance to water and increases in water permeation fluxes. Preparation of the L-TFC-90 membranes with various thicknesses (from $0.47 \mu \mathrm{m}$ to $1.75 \mu \mathrm{m}$ ) of the separative layer has been achieved by adjusting the concentrations of the lignin/ PVA casting solutions (2-5 wt\%) and gap thicknesses of the casting knife. As shown in Fig. 4, all the L-TFC-90 membranes show satisfactory salt rejection of $99.93 \%$ to $99.97 \%$. The high salt rejection of the L-TFC-90 membranes support its pinholefree structure. Reduction of the separation layer thickness does not bring a negative effect on the salt rejection performance of the membranes and significantly increases the water permeation fluxes to $6.1 \mathrm{~kg} \mathrm{~h}^{-1} \mathrm{~m}^{-2}$. It is noteworthy that the water permeation fluxes of the membrane are linearly proportional to the reciprocal of the separation layer thickness, indicating that the water permeation through the membrane could follow the Fickian behavior in the solution-diffusion model. ${ }^{40}$ The water permeation flux of the L-TFC-90 membrane could be further increased by increasing the operation temperatures. While

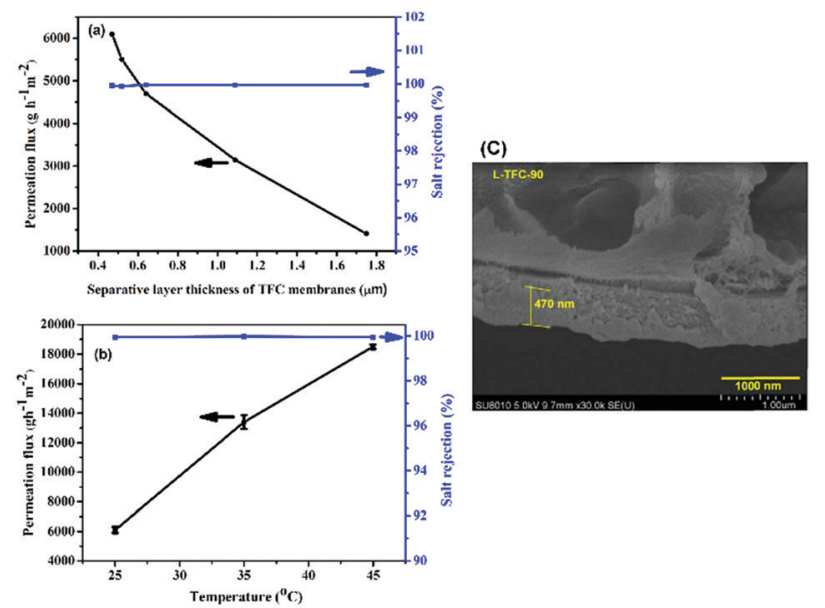

Fig. 4 Pervaporation desalination performance of (a) L-TFC-90 membranes with different thicknesses of separation layers and (b) L-TFC-90 membrane with a $0.47 \mu \mathrm{m}$ separation layer at different temperatures. Feeding solution: 3.5 wt\% $\mathrm{NaCl}_{(\mathrm{aq})}$; (c) the SEM micrograph of L-TFC-90 membrane with a $0.47 \mu \mathrm{m}$ separation layer. increasing the operation temperature from $25{ }^{\circ} \mathrm{C}$ to $45{ }^{\circ} \mathrm{C}$, the water permeation flux increases from $6.1 \mathrm{~kg} \mathrm{~h}^{-1} \mathrm{~m}^{-2}$ to $18.5 \mathrm{~kg} \mathrm{~h}^{-1} \mathrm{~m}^{-2}$ without any sacrifice of the salt rejection. Although operation of the desalination process at high temperatures requires extra consumption of energy, the L-TFC-90 membrane might be applicable to systems with external waste heat/energy since it demonstrate a high flux at $45^{\circ} \mathrm{C}$. Moreover, the lignin-based membrane did not exhibit satisfactory stabilization for operation at high temperatures, as the recorded permeation fluxes having a relatively high number of errors. This fact could be attributed to the small amount of PVA binder, which is not enough to provide satisfactory stabilization of the lignin component. Further studies on the optimization between membrane stability and permeation fluxes are worthy of investigation. The desalination performance of the L-TFC-90 membrane is comparable to the data reported in the literature (Table 2). The activation energy for the water permeation through the membrane is calculated to be about $44.0 \mathrm{~kJ} \mathrm{~mol}^{-1}$. Compared to the values of 16 to $51 \mathrm{~kJ} \mathrm{~mol}^{-1}$ reported in the literature ${ }^{41}$ the activation energy is in the relatively high region to suggest a high energy barrier for water permeation through the membrane, which could be an overall effect of temperature on the factors affecting the water permeation including water solubility and diffusivity within the membrane and the driving force of the permeation. ${ }^{41}$

The stability of the L-TFC-90 membrane with a separation layer thickness of $0.47 \mu \mathrm{m}$ has been employed with the tests discussed below. First, the stability of the membrane in a $20 \mathrm{~h}$ pervaporation desalination operation has been examined (Fig. 5). The membrane keeps its high salt rejection above $99.95 \%$ in the duration of tests. The water permeation fluxes stably vary at about $6.0 \mathrm{~kg} \mathrm{~h}^{-1} \mathrm{~m}^{-2}$, warranting the membrane stability for continuous operation. In another test, the membrane is soaked in the feeding solution $\left(3.5 \mathrm{wt} \% \mathrm{NaCl}_{(\mathrm{aq})}\right)$ and picked out for pervaporation desalination measurements at certain periods. In a 22 days test, the membrane still maintains its stability with high salt rejections of above 99.95\% and stable water permeation fluxes.

\section{Salt effects on the pervaporation desalination performance of} the L-TFC-90 membrane

The ability of the pervaporation desalination membrane facing to feeding solutions containing various salt concentrations and various types of salts is examined. While $\mathrm{NaCl}$ is employed as the salt, the feeding solutions in various concentrations from $3.5 \mathrm{wt} \%$ to $15 \mathrm{wt} \%$ have been applied for the tests. The membrane still exhibits high salt rejection in the tests (Fig. 6). The water permeation fluxes could keep at a high level for the feeding solutions of concentrations below $7.0 \mathrm{wt} \%$. The membrane is still workable for concentrated $\mathrm{NaCl}_{(\mathrm{aq})}$ up to $15 \mathrm{wt} \%$ although with a significant drop of permeation fluxes. The results demonstrate that the lignin-based TFC membrane has high potential for applications in high salinity water treatment. ${ }^{42}$ The effect of types of salts on the pervaporation desalination performance of the L-TFC-90 membrane has been examined. ${ }^{18}$ The membrane shows similar pervaporation desalination results for $\mathrm{NaCl}, \mathrm{KCl}$, and $\mathrm{LiCl}$. 
Table 2 Pervaporation dehydration on $3.5 \mathrm{wt} \% \mathrm{NaCl}_{(\mathrm{aq})}$ with various membranes reported in literature and this work

\begin{tabular}{|c|c|c|c|c|c|c|c|}
\hline $\begin{array}{l}\text { Materials for } \\
\text { separation layer }^{a}\end{array}$ & $\begin{array}{l}\text { Membrane } \\
\text { substrate }\end{array}$ & Temp. $\left({ }^{\circ} \mathrm{C}\right)$ & $\begin{array}{l}\text { Separation layer } \\
\text { thickness }(\mu \mathrm{m})\end{array}$ & Flux $\left(\mathrm{kg} \mathrm{h}^{-1} \mathrm{~m}^{-2}\right)$ & $\begin{array}{l}\text { Permeability } \\
\left(\mathrm{kg} \mu \mathrm{m} \mathrm{h}^{-1} \mathrm{~m}^{-2}\right)\end{array}$ & $\begin{array}{l}\text { Salt } \\
\text { rejection (\%) }\end{array}$ & Ref. \\
\hline PVA & PSf hollow fiber & 70 & 0.1 & 7.4 & 0.74 & 99.9 & 6 \\
\hline PVA & PSf UF & 70 & 1.12 & 60.8 & 68.1 & 99.8 & 44 \\
\hline PVA & PAN electrospun mat & 75 & 0.73 & 234.9 & 171 & 99.7 & 4 \\
\hline GO & PAN UF & 90 & 0.1 & 65.1 & 6.51 & 99.8 & 45 \\
\hline Cellulose triacetate $/ \mathrm{Al}_{2} \mathrm{O}_{3}$ & - & 70 & 13 & 6.7 & 87.1 & 99.8 & 47 \\
\hline PVA & PTFE & 75 & 2.6 & 120 & 312 & - & 48 \\
\hline MXene & PAN UF & 30 & 0.06 & 48.2 & 2.90 & 99.5 & 18 \\
\hline Lignin & PAN UF & 45 & 0.47 & 18.5 & 8.70 & $>99.95$ & This study \\
\hline
\end{tabular}
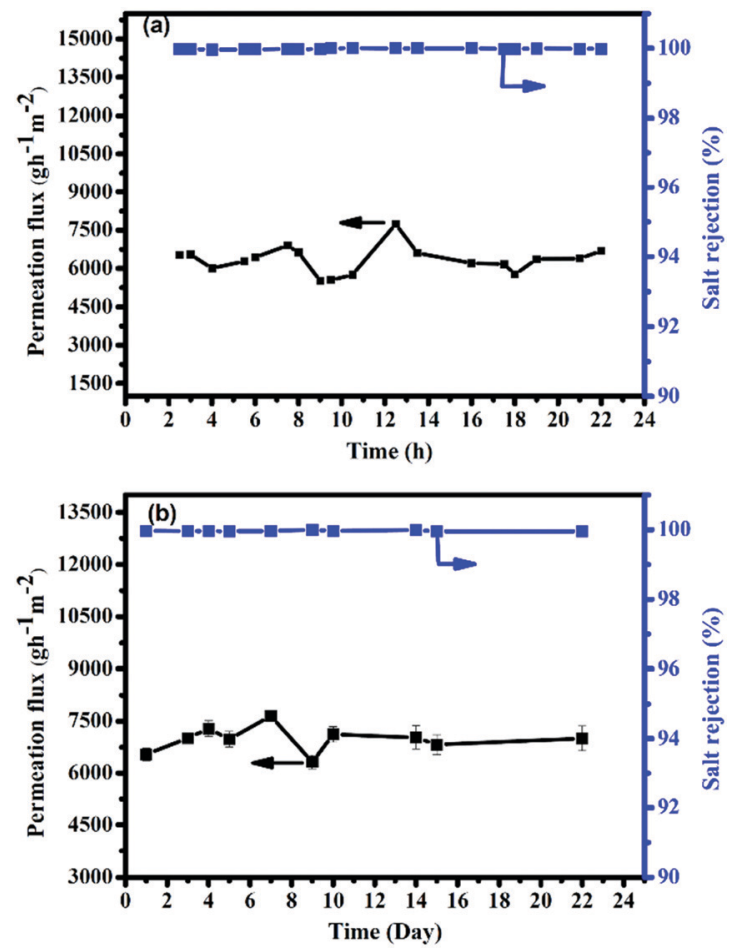

Fig. 5 Long-term operation tests on the pervaporation desalination performance of L-TFC- 90 membranes with a $0.47 \mu \mathrm{m}$ separation layer at $25^{\circ} \mathrm{C}$ with a $3.5 \mathrm{wt} \% \mathrm{NaCl}_{(\mathrm{aq})}$ as the feeding solution. (a) A $20 \mathrm{~h}$ continuing pervaporation desalination operation and (b) the membrane is soaked in the feeding solution and picked out for pervaporation desalination measurements in a 22 days test.

While the anion changes from $\mathrm{Cl}^{-}(\mathrm{NaCl})$ to $\mathrm{Br}^{-}$(NaBr), the water permeation flux drops from $5.9 \mathrm{~g} \mathrm{~h}^{-1} \mathrm{~m}^{-2}$ to $4.2 \mathrm{~kg} \mathrm{~h}^{-1} \mathrm{~m}^{-2}$ due to the relatively large size of $\mathrm{Br}^{-}$. Compared to $\mathrm{Cl}^{-}$ions, diffusion of $\mathrm{Br}^{-}$ions into the lignin layer is relatively difficult. A small swelling effect happens to the membrane, consequently, to result in a small water permeation flux. Similar results have been observed with the divalent cation salts $\left(\mathrm{CaCl}_{2}, \mathrm{MgCl}_{2}\right.$, and $\mathrm{MgSO}_{4}$ ). The high permeation flux recorded on $\mathrm{NaNO}_{3}$ salt could be attributed to the high affinity between lignin and nitrate
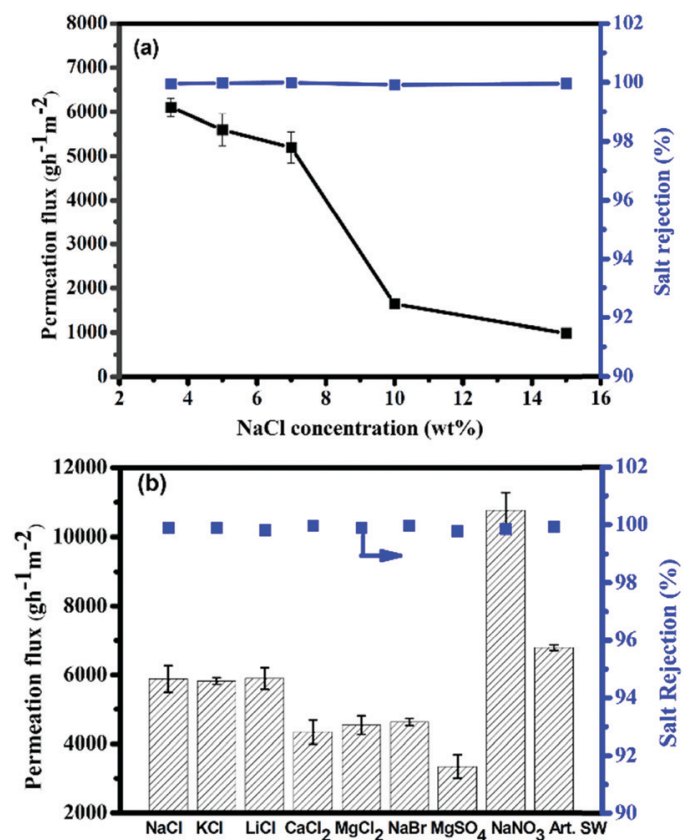

Fig. 6 Pervaporation desalination performance of L-TFC-90 membrane with a $0.47 \mu \mathrm{m}$ separation layer to various feeding solution. (a) $\mathrm{NaCl}_{(\mathrm{aq})}$ in different concentrations and (b) different salt aqueous solutions $(0.1 \mathrm{M})$ and artificial seawater ( $\mathrm{NaCl}$ : $0.46 \mathrm{M}$; $\mathrm{MgSO}_{4}: 0.013 \mathrm{M} ; \mathrm{CaCl}_{2}: 0.01 \mathrm{M} ; \mathrm{KCl}$ : $0.01 \mathrm{M} ; \mathrm{NaHCO}_{3}: 0.002 \mathrm{M} ; \mathrm{NaBr}: 0.006 \mathrm{M}$ ).

ions,${ }^{51}$ which shows high tendency of diffusion into the lignin membrane. Furthermore, the test employing an artificial seawater as the feeding solution has been done (Table 3). The pervaporation desalination performance (water permeation flux: $20.4 \mathrm{~kg} \mathrm{~h}^{-1} \mathrm{~m}^{-2}$; salt rejection: $>99.95 \%$ at $45{ }^{\circ} \mathrm{C}$ ) which is superior over the data reported to polymeric membranes (Table 3). Although the membranes based on MXene and GO showed relatively high permeation fluxes, the high cost of the utilized materials and complicated fabrication processes of the membranes might limit their practical applications. On the other hand, the lignin-based membranes utilize renewable ad low-cost raw materials and employ simple fabrication processes. 
Table 3 Pervaporation desalination on artificial seawater with different membranes reported in literature and this work

\begin{tabular}{lllll}
\hline $\begin{array}{l}\text { Materials for } \\
\text { separation layer }\end{array}$ & $\begin{array}{l}\text { Temp. } \\
\left({ }^{\circ} \mathrm{C}\right)\end{array}$ & $\begin{array}{l}\text { Permeation } \\
\text { flux }\left(\mathrm{kg} \mathrm{h}^{-1} \mathrm{~m}^{-2}\right)\end{array}$ & $\begin{array}{l}\text { Salt rejection } \\
(\%)\end{array}$ & Ref. \\
\hline S-SEBS $35.0 \%$ & 60 & N.A. & $>99.5$ & 43 \\
PVDF/PVP & 60 & 1.6 & 99.9 & 49 \\
MXene & 65 & 52.94 & $>99.5$ & 16 \\
GO & 75 & 31.3 & $>99.7$ & 50 \\
Lignin & 45 & 20.4 & $>99.95$ & This work
\end{tabular}

${ }^{a}$ S-SEBS: sulfonated styrene/ethylene-butylene/styrene (S-SEBS) triblock polymer; PVDF/PVP: poly(vinylidene difluoride)/poly(vinyl pyridine) mixture; GO: graphene.

The features warrant the application potential of the L-TFC-90 membrane for production of drinkable water from seawater. ${ }^{43}$

\section{Conclusions}

Lignin, a polymeric material from biomass, has been demonstrated to be an effective raw material for fabrication of separation membranes. The results first explore that the lignin-based TFC membranes could be obtained with conventional solution-casting processes. Based on the hydrophilicity of lignin, the lignin-based TFC membranes show satisfactory performance on pervaporation desalination on high salinity water treatments and production of drinkable water from seawater. This work has successfully demonstrated a process using sustainable materials for wastewater treatments and water resource generation. Continuing studies on adjusting the membrane structures might further enhance the desalination performance. Moreover, lignin is potential for studies on other membrane applications like ultrafiltration and nanofiltration.

\section{Conflicts of interest}

There are no conflicts to declare.

\section{Acknowledgements}

The authors thank the Ministry of Science and Technology (MOST) of Taiwan for the financial support of this work (Grant No. MOST-108-2221-E-007-015-MY3 and MOST-109-3116-F-011002-CC1).

\section{Notes and references}

1 Q. Wang, N. Li, B. Bolto, M. Hoans and Z. Xie, Desalination by pervaporation: a review, Desalination, 2016, 387, 46-60.

2 W. Kaminski, J. Marszalek and E. Tomczak, Water desalination by pervaporation - Comparison of energy consumption, Desalination, 2018, 433, 89-93.

3 W. Zhong, Q. Li, X. Zhao and S. Chen, Membrane Preparation for Unconventional Desalination by Membrane Distillation and Pervaporation, Environmental Chemistry for a Sustainable World, 2020, vol. 42, pp. 265-293.
4 Y. L. Xue, J. Huang, C. H. Lau, B. Cao and P. Li, Tailoring the molecular structure of crosslinked polymers for pervaporation desalination, Nat. Commun., 2020, 11, 1461.

5 C. Cheng, L. Shen, X. Yu, Y. Yang, X. Li and X. Wang, Robust construction of a graphene oxide barrier layer on a nanofibrous substrate assisted by the flexible poly(vinylalcohol) for efficient pervaporation desalination, J. Mater. Chem. A, 2017, 5, 3558-3568.

6 S. G. Chaudhri, B. H. Rajai and P. S. Singh, Preparation of ultra-thin poly(vinyl alcohol) membranes supported on polysulfone hollow fiber and their application for production of pure water from seawater, Desalination, 2015, 367, 272-284.

7 S. G. Chaudhri, J. C. Chaudhari and P. S. Singh, Fabrication of efficient pervaporation desalination membrane by reinforcement of poly(vinyl alcohol)-silica film on porous polysulfone hollow fiber, J. Appl. Polym. Sci., 2018, 135, 45718.

8 R. Zhang, B. Liang, T. Qu, B. Cao and P. Li, Highperformance sulfosuccinic acid cross-linked PVA composite pervaporation membrane for desalination, Environ. Technol., 2019, 40, 312-320.

9 A. Selim, A. J. Toth, E. Haaz, D. Fozer, A. Szanyi, N. Hegyesi and P. Mizsey, Preparation and characterization of PVA/GA/ Laponite membranes to enhance pervaporation desalination performance, Sep. Purif. Technol., 2019, 221, 201-210.

10 G. Yang, Z. Xie, M. Cran, D. Ng and S. Gray, Enhanced desalination performance of poly(vinyl alcohol)/carbon nanotube composite pervaporation membranes via interfacial engineering, J. Membr. Sci., 2019, 579, 40-51.

11 D. A. R. Olegário da Silva, L. C. B. Zuge and A. de Paula, Scheer, Preparation and characterization of a novel green silica/PVA membrane for water desalination by pervaporation, Sep. Purif. Technol., 2020, 247, 116852.

12 F. U. Nigiz, Graphene oxide-sodium alginate membrane for seawater desalination through pervaporation, Desalination, 2020, 485, 114465.

13 H. Halakoo and X. Feng, Layer-by-layer assembly of polyethyleneimine/graphene oxide membranes for desalination of high-salinity water via pervaporation, Sep. Purif. Technol., 2020, 234, 116077.

14 J. Sun, X. Qian, Z. Wang, F. Zeng, H. Bai and N. Li, Tailoring the microstructure of poly(vinyl alcohol)-intercalated graphene oxide membranes for enhanced desalination performance of high-salinity water by pervaporation, J. Membr. Sci., 2020, 599, 117838.

15 W. Cha-Umpong, E. Hosseini, A. Razmjou, M. Zakertabrizi, A. H. Korayem and V. Chen, New molecular understanding of hydrated ion trapping mechanism during thermallydriven desalination by pervaporation using GO membrane, J. Membr. Sci., 2020, 598, 117687.

16 G. Liu, J. Shen, Q. Liu, G. Liu, J. Xioan, J. Yang and W. Jin, Ultrathin two-dimensional MXene membrane for pervaporation desalination, J. Membr. Sci., 2018, 548, 548-558.

17 M. Ding, H. Xu, W. Chen, G. Yang, Q. Kong, D. Ng, T. Lin and Z. Xie, 2D laminar maleic acid-crosslinked MXene membrane with tunable nanochannels for efficient and 
stable pervaporation desalination, J. Membr. Sci., 2020, 600, 117871.

18 I. Ihsanullah, Potential of MXenes in water desalination: current status and perspectives, Nano-Micro Lett., 2020, 12, 1443.

19 J. Zakzeski, P. C. A. Bruijnincx, A. L. Jongerius and B. M. Weckhuysen, The catalytic valorization of lignin for the production of renewable chemicals, Chem. Rev., 2010, 110, 3552-3599.

20 P. Azadi, O. R. Inderwildi, R. Farnood and D. A. King, Liquid fuels, hydrogen and chemicals from lignin: a critical review, Renewable Sustainable Energy Rev., 2013, 21, 506-523.

21 C. Xu, R. Arneil, D. Arancon, J. Labidi and R. Luque, Lignin depolymerisation strategies: towards valuable chemicals and fuels, Chem. Soc. Rev., 2014, 43, 7485-7500.

22 W. Schutyser, T. Renders, S. Van den Bosch, S.-F. Koelewijn, G. T. Beckham and B. F. Sels, Chemicals from lignin: an interplay of lignocellulose fractionation, depolymerisation, and upgrading, Chem. Soc. Rev., 2018, 47, 852-908.

23 C. Zhang and F. Wang, Catalytic lignin depolymerization to aromatic chemicals, Acc. Chem. Res., 2020, 53, 470-484.

24 M. N. Collins, M. Nechifor, F. Tanasă, M. Zănoagă, A. McLoughlin, M. A. Stróżyk, M. Culebras and C.-A. Teacă, Valorization of lignin in polymer and composite systems for advanced engineering applications - A review, Int. J. Biol. Macromol., 2019, 131, 828-849.

25 A. Khan, J. C. Colmenares and R. Gläser, Lignin-based composite materials for photocatalysis and photovoltaics, in Lignin Chemistry, Topics in Current Chemistry Collections, ed. L. Serrano, R. Luque and B. Sels, Springer, Cham, 2018.

26 K. Roy, S. C. Debnath and P. Potiyaraj, A review on recent trends and future prospects of lignin based green rubber composites, J. Polym. Environ., 2020, 28, 367-387.

27 Z. J. Shi and M. G. Ma, Synthesis, structure, and applications of lignin-based carbon materials: a review, Sci. Adv. Mater., 2019, 11, 18-32.

28 J. Ye, Y. Cheng, L. Sun, M. Ding, C. Wu, D. Yuan, X. Zhao, C. Xiang and C. Jia, A green SPEEK/lignin composite membrane with high ion selectivity for vanadium redox flow battery, J. Membr. Sci., 2019, 572, 110-118.

29 M. E. González-López, J. R. Robledo-Ortíz, D. Rodrigue and A. A. Pérez-Fonseca, Highly porous lignin composites for dye removal in batch and continuous-flow systems, Mater. Lett., 2020, 63, 27289.

30 M. Yong, Y. Zhang, S. Sun and W. Liu, Properties of polyvinyl chloride (PVC) ultrafiltration membrane improved by lignin: hydrophilicity and antifouling, J. Membr. Sci., 2019, 575, 50-59.

31 Z. Ding, L. Zhong, X. Wang and L. Zhang, Effect of lignincellulose nanofibrils on the hydrophilicity and mechanical properties of polyethersulfone ultrafiltration membranes, High Perform. Polym., 2016, 28, 1192-1200.

32 F. Zhang, Y. Wu, W. Li, W. Xing and Y. Wang, Depositing lignin on membrane surfaces for simultaneously upgraded reverse osmosis performances: an upscalable route, AIChE J., 2017, 63, 2221-2231.
33 A. Bahi, J. Shao, M. Mohseni and F. K. Ko, Membranes based on electrospun lignin-zeolite composite nanofibers, Sep. Purif. Technol., 2017, 187, 207-213.

34 Y. T. Chen, Y. L. Liao, Y. M. Sun, C. C. Hu, J. Y. Lai and Y. L. Liu, Lignin as an effective agent for increasing the separation performance of crosslinked polybenzoxazine based membranes in pervaporation dehydration application, J. Membr. Sci., 2019, 578, 156-162.

35 B. K. Su, C. H. Chang, Y. M. Sun, C. C. Hu, J. Y. Lai and Y. L. Liu, Porous membranes of thermosetting polybenzoxazine resins with interconnected-pores for organic solvent microfiltration, J. Membr. Sci., 2019, 586, 267-273.

36 Q. F. An, M. B. M. Y. Ang, Y. H. Huang, S. H. Huang, Y. H. Chiao, C. L. Lai, H. A. Tsai, W. S. Hung, C. C. Hu, Y. P. Wu and K. R. Lee, Microstructural characterization and evaluation of pervaporation performance of thin-film composite membranes fabricated through interfacial polymerization on hydrolyzed polyacrylonitrile substrate, J. Membr. Sci., 2019, 583, 31-39.

37 W. S. Hung, C. H. Tsou, M. De Guzman, Q. F. An, Y. L. Liu, Y. M. Zhang, C. C. Hu, K. R. Lee and J. Y. Lai, Crosslinking with diamine monomers to prepare composite grapheneoxide-framework membranes with varying d-spacing, Chem. Mater., 2014, 26, 2983-2990.

38 F. J. Liou and Y. J. Wang, Preparation and characterization of crosslinked and heat-treated PVA-MA films, J. Appl. Polym. Sci., 1996, 59, 1395-1403.

39 N. W. Oh, J. Jegal and K. H. Lee, Preparation and characterization of nanofiltration composite membranes using polyacrylonitrile (PAN). II. Preparation and characterization of polyamide composite membranes, J. Appl. Polym. Sci., 2001, 80, 2729-2736.

40 N. Işiklan and O. Şanli, Separation characteristics of acetic acid-water mixtures by pervaporation using poly(vinyl alcohol) membranes modified with malic acid, Chem. Eng. Process., 2005, 44, 1019-1027.

41 Q. Wang, N. Li, B. Bolto, M. Hoang and Z. Xie, Desalination by pervaporation: a review, Desalination, 2016, 387, 46-60.

42 H. Y. Zhang, J. L. Wen, Q. Shao, A. Yuan, H. T. Ren, F. Y. Luo and X. L. Zhang, Fabrication of La/Y-codoped microporous organosilica membranes for high-performance pervaporation desalination, J. Membr. Sci., 2019, 584, 353-363.

43 Q. Wang, Y. Lu and N. Li, Preparation, characterization and performance of sulfonated poly(styrene-ethylene/butylenestyrene) block copolymer membranes for water desalination by pervaporation, Desalination, 2016, 390, 33-46.

44 Q. Li, B. Cao and P. Li, Fabrication of high-performance pervaporation desalination composite membranes by optimizing the support layer structures, Ind. Eng. Chem. Res., 2018, 32, 11178-11185.

45 B. Liang, W. Zhan, G. Qi, S. Lin, Q. Nan, Y. Liu, B. Cao and K. Pan, High performance graphene oxide/polyacrylonitrile composite pervaporation membranes for desalination applications, J. Mater. Chem. A, 2015, 3, 5140-5147.

46 M. Elma, C. Yacou, J. C. Diniz da Costa and D. K. Wang, Performance and long term stability of mesoporous silica membranes for desalination, Membranes, 2013, 3, 136-150. 
47 I. Prihatiningtyasa, G. A. Gebreslasea and B. Van, der Bruggen, Incorporation of $\mathrm{Al}_{2} \mathrm{O}_{3}$ into cellulose triacetate membranes to enhance the performance of pervaporation for desalination of hypersaline solutions, Desalination, 2020, 474, 114198.

48 J. Meng, C. H. Lau, Y. Xue, R. Zhang, B. Cao and P. Li, Compatibilizing hydrophilic and hydrophobic polymers via spray coating for desalination, J. Mater. Chem. A, 2020, 8, 8462-8468.
49 F. U. Nigiz and N. D. Hilmioglu, Pervaporative desalination of seawater using a polyvinylidene fluoride based membrane, Water Supply, 2018, 18, 1674-1681.

50 K. Xu, B. Feng, C. Zhou and A. Huang, Synthesis of highly stable graphene oxide membranes on polydopamine functionalized supports for seawater desalination, Chem. Eng. Sci., 2016, 146, 159-165.

51 M. Norgren, H. Edlund and L. Wagberg, Aggregation of lignin derivatives under alkaline conditions. Kinetics and aggregation structure, Langmuir, 2002, 18, 2859-2865. 